\title{
US - Lamb \\ United States - Safeguard Measures on Imports of Fresh, Chilled or Frozen Lamb Meat from New Zealand and Australia: What Should be Required of a Safeguard Investigation?*
}

HENRIK HORN AND PETROS C. MAVROIDIS

\section{Background}

The United States (US) imposed, in July 1999, a safeguard on lamb meat, in the form of tariff rate import quotas, which were to be applied for a period of three years. The measure was based on findings by the US International Trade Commission that increased imports of lamb meat were a substantial cause of threat of serious injury to the US industry producing the like product. Following complaints by New Zealand and Australia that the measure was inconsistent with Articles I, II and XIX of GATT 1994, and several provisions of the Agreement on Safeguards, the World Trade Organization (WTO) Dispute Settlement Body established, in November 1999, a panel to review the consistency of the US measure with the mentioned WTO rules.

The Panel found that: ${ }^{1}$

* This study reviews the WTO Appellate Body Decision United States - Safeguard Measures on Imports of Fresh, Chilled or Frozen Lamb Meat from New Zealand and Australia (WT/DS177/AB/R, WT/DS178/AB/R, May 1, 2001). It is prepared for the American Law Institute project "Principles of Trade Law: the World Trade Organization." We are grateful to, in particular, Bill Davey, Wilfred J. Ethier, and Joseph Weiler for helpful discussions. We have also benefited from discussions with Eyal Benvenisti, David Strömberg, and Jonas Vlachos as well as with the participants in ALI meetings in Philadelphia on October 24-25, 2002, and February 6-7, 2003.

${ }^{1}$ United States - Safeguard Measures on Imports of Fresh, Chilled or Frozen Lamb Meat from New Zealand and Australia, WT/DS177/R, WT/DS178/R, December 21, 2000. 
(i) the US had failed to demonstrate that the import surge was the result of unforeseen developments as required by Article 1 SGA, which incorporates by reference Article XIX GATT;

(ii) the US had made too broad a definition of domestic industry inconsistent with Article 2.1 and Article 4.1c of the Agreement on Safeguards;

(iii) the Complainants failed to establish the deficiency of the methodology employed by the US International Trade Commission to establish threat of serious injury (and hence rejected their claims in this respect);

(iv) the US International Trade Commission investigation based its finding on non-representative data, inconsistent with the requirements of the Agreement on Safeguards; and

(v) the US International Trade Commission investigation did not establish, as required by Article 4.2 SGA, a causal link between increased imports and the threat of serious injury, nor that this threat could not be attributed to other factors.

The Panel thus found that the US had acted inconsistently with Article XIX.1.a GATT and with several provisions in the Agreement on Safeguards.

All three parties to the dispute appealed the Panel Report. In its report, ${ }^{2}$ the Appellate Body $(\mathrm{AB})$ :

(i) upheld the Panel's finding that the US International Trade Commission had failed to demonstrate unforeseen developments;

(ii) agreed with the Panel that the US International Trade Commission had used too wide a definition of domestic industry and had relied on non-representative data;

(iii) in contrast to the Panel, found the method employed by the US International Trade Commission to assess the threat of serious injury to be deficient; and

(iv) reversed the Panel's interpretation of the causality requirement, but for reasons other than those advanced by the Panel upheld the finding that the US International Trade Commission did not fulfill this requirement, nor the non-attribution requirement.

2 United States - Safeguard Measures on Imports of Fresh, Chilled or Frozen Lamb Meat from New Zealand and Australia (WT/DS177/AB/R, WT/DS178/AB/R, May 1, 2001). 
The purpose of this study is to provide an economic and legal analysis of this dispute, subsequently referred to as US - Lamb. In order to set the stage for the discussion to come, we will start in the next section by sketching a theory of an economic rationale for safeguard provisions in trade agreements. Section 3 provides the context of the legal dispositions that we discuss in the rest of the paper. Section 4 then very briefly lays out the legal provisions of particular relevance to this dispute, which are further analyzed in more detail in section 5 ("unforeseen developments"), Section 6 (“... causal link between increased imports ... and serious injury or threat thereof ..."), and in section 7 (“... of the effects of obligations incurred under this Agreement...”). Section 8 provides some concluding remarks.

\section{The role of safeguards in trade agreements}

Safeguards are temporary trade barriers, and, as such, hurt trading partners. A natural question is, therefore, whether they could nevertheless be defended from an efficiency point of view, that is, whether the existence of such an instrument in a trade agreement increases the "size of the cake" that its members share. We will argue that safeguards may indeed play such a role, but that their practical implementation is beset with the risk of abuse. ${ }^{3}$

\subsection{The case for safeguards}

The economic environment is constantly changing: new products and production technologies are discovered, consumer tastes change, governments come and go, there are wars, investments are made, new firms see the light of day. For a trade agreement to be fully efficient, it would need to adapt to these changes. This adaptation could be fully achieved only under very special circumstances. If the parties could perfectly foresee the path of events, then they could sign a contract at the outset that would specify how the contract terms would change along this path. In the absence of such information, the parties may renegotiate the contract any time a change occurs. Alternatively, the parties could write a "fully state

3 See Sykes $(1990,1991)$ for analysis of the role of safeguards in trade agreements, in particular as viewed from the perspective of public choice theory. See also Deardorff's (1987) treatment of the role of tariff and non-tariff safeguards when social preferences are represented by a Corden "conservative social welfare function." 
contingent" contract, which would detail commitments for each possible outcome of the underlying economic environment. ${ }^{4}$

Under either of these circumstances, it would be possible to specify a trade contract that expost ensures the desirable levels of trade. If desirable, this contract could also allow for a gradual adjustment to the changed environment. Hence, in neither case would there be a role for any provision that allowed for an ex post change in tariff bindings.

Tariff bindings in actual trade agreements are typically not conditioned on external events, however. There is therefore a need for instruments that allow for ex post adjustment of effective levels of bindings - that is, for escape clauses - and the GATT includes several provisions to this effect. Article XII enables the adoption of protective measures in response to economy-wide monetary disturbances, but most contingent protection instruments are enacted as remedies to problems in specific industries. Article XXVIII permits renegotiation with other contracting parties of particular bindings, and might thus allow for more long-run, but also presumably more time-consuming, solutions to problems of expost inefficient tariff bindings.

What is, then, the role of Article XIX GATT safeguards in this arsenal of escape clauses? Safeguards may be unilaterally imposed, and might for this reason represent a quicker response to changes in the economic environment in particular industries (depending on the administrative requirements imposed on safeguard investigations) than for instance an Article XXVIII renegotiation. ${ }^{5}$ But Article XIX GATT safeguards are not the only measures that can be unilaterally imposed - both anti-dumping duties and countervailing duties can be imposed without negotiation with the exporting country. However, Article XIX GATT safeguards differ from the latter measures in that they are meant to temporarily slow the pace of adjustment to changes in the external economic environment, whereas anti-dumping measures and countervailing duties can be in place for as long as the dumping or subsidization continues. ${ }^{6}$

${ }^{4}$ The difference between the two scenarios is that in the former, the contract would specify the commitments of the Members at each date. These would then vary over time in response to changes in the external environment. In the latter case, since the realization of these external events would be unknown at the contracting date, the contract would specify for each date commitments for each possible realization. This would thus be a significantly larger contract, but would in principle achieve the same thing as the first contract.

${ }^{5}$ We implicitly assume that there are costs associated with contracting, so that the parties do not negotiate a new contract each time the environment changes.

${ }^{6}$ Suppose that the European Community imposes a four-year safeguard measure on steel. At the end of this period, the EC has two options: either they extend the measure for 
The question thus arises of whether such an instrument can be defended from an economic point of view, in the sense of whether it might enhance the efficiency of the trade agreement, that is, increase the size of the "pie" the parties to the contract share through the agreement.

As we will argue below, in order for there to be a need for an instrument seeking to slow the adjustment speed, it does not suffice that tariff bindings be rigid. But a combination of rigid bindings and "adjustment costs" that depend on the pace of adjustment may indeed provide a role for safeguards.

\subsubsection{Safeguards as means to reduce adjustment costs}

The economic notion of "adjustment costs" is amorphous. ${ }^{7}$ The interpretation we have in mind refers to the cost accruing due to the transition from one equilibrium to another (and does thus not involve a comparison of the final outcome with the initial situation). To define more precisely such costs we need to agree on the criterion according to which costs are evaluated. We here start by considering adjustment costs from the point of view of social welfare maximization. But we will discuss other objectives as well.

Consider an import-competing domestic industry - lamb-meat production, say - that has suffered a severe negative shock - foreign capacity has permanently expanded, and prices have fallen significantly as a result. As matters stand, the industry has to shed 12,000 people. Suppose first that they could all immediately find employment in the beef-meat industry, but at lower wages. This lowering of the wage would obviously be costly to workers, but would not be considered as an adjustment cost, since it would simply reflect differences between two equilibria, with no transitional period in between: the lowering of the wage is not a cost incurred during the transition from one employment situation to another.

Let it now take each worker six months to find new employment, no matter what the circumstances, and during this period the worker has to

up to four years (Article 7.2 SGA), or alternatively they do not extend the measure. In the first case, assuming the EC decided to extend the original safeguard for four years, it has to wait for another eight years before imposing a safeguard measure on steel anew. In the second case, they have to wait for four years. No similar rule applies in the case of anti-dumping, where after the sunset of a measure five years after its imposition (11.3 Anti-dumping Agreement), the importing country can effectively extend the anti-dumping measure.

7 Trade theory often pays lip service to the existence of adjustment costs, but relatively little work has been done on their sources and consequences. For analysis of some basic aspects of adjustment costs, see Mussa (1981) and Neary (1981), and other contributions in the volume edited by Jagdish Bhagwati (Bhagwati, 1981). 
remain unproductive. This would be a social adjustment cost: during the transition period the economy is temporarily producing at less than its long-run full capacity. But this cost does not depend on the speed of adjustment, since each worker by assumption has to be unemployed for six months, no matter what. This period of reduced output is essentially an unavoidable investment in a more efficient production pattern. It would hence not provide a rationale for a safeguard that would gradually move workers into the beef industry, since such a measure would not affect the total magnitude of adjustment costs, but would just cause a costly delay to the necessary adjustment.

As a third possibility, assume that each quarter 6,000 vacancies are opened in the beef-meat industry. A finely tuned safeguard that gradually reduced the work force in the lamb-meat industry could then ensure that 6,000 workers were reallocated during the first quarter, and another 6,000 the next, without anyone having to be temporarily unemployed. On the other hand, if all 12,000 had to leave the lamb meat industry immediately, 6,000 of them would be unemployed for a quarter. ${ }^{8}$ The speed at which the adjustment takes place thus affects the aggregate adjustment costs, and there is a case for a safeguard. This provides efficiency-enhancing rationale for safeguards: to temporarily reduce the pace of adjustment in order to reduce adjustment costs.

There are several things to note:

1. The example presumes that the alternative to the safeguard is that all 12,000 workers immediately leave the industry. But why do not 6,000 workers remain in the lamb industry during the first quarter and offer to work at sufficiently low wages for the industry to want to retain them? If wages were reduced this way, there would be no unnecessary loss of output during the transition, and hence no case for a safeguard (or at least a weaker case). The reason must be some form of inflexibility in the wage, arising from, for instance, labor union resistance to wage cuts, or minimum wage legislation.

More generally, in order for government intervention to have an efficiency-enhancing role to play, the privately perceived incentives to cope with adjustment must be incorrect from a social point of view (or from a government point of view). If the private sector puts the same emphasis on these costs as the government, and has access to

${ }^{8}$ To make the case even stronger, suppose that workers lose productive skills during their period of unemployment, or lose self-confidence and thus search less intensively for new jobs, or suffer mentally from the unemployment. 
the same (possibly imperfect) information about the future evolution of the economy, and the economy is not distorted in other respects, it does not suffice that there are adjustment costs that depend on the pace of adjustment, for a role for safeguards to exist. For instance, in the example above, the implicitly assumed wage rigidity implied that the cost of labor perceived by the lamb meat industry exceeded the true social cost of this labor, which should reflect the opportunity cost of workers.

2. The example presumes that the shock to international prices is permanent, and the economy will therefore eventually have to change to the new circumstances. If the shock were temporary, a safeguard could under certain circumstances serve a slightly different role, by preventing adjustment costs from arising from resources first moving out and then back into the industry. Again, for such a role to arise it must be that the owners of these resources do not have the right incentives, as perceived from a social point of view, to avoid these adjustment costs by letting resources remain in the industry during the temporary slump.

3. The argument above helps identify circumstances under which a safeguard might improve matters relative to a situation where nothing is done. It has not been argued, however, that an import restriction would be the best way of coping with the problem. To start with, if the source of the wage rigidity cannot be removed, it might still be preferable to use employment subsidies, or production subsidies, since these do not distort consumer prices to the same extent. ${ }^{9}$

4. The examples above presume for simplicity's sake that the government has full information about relevant aspects of the future. In practice, there is of course often considerable uncertainty about whether negative shocks are transitory or permanent, and this uncertainty may influence the appropriate length and magnitude of a safeguard measure. But this uncertainty does not in itself add any reason for a government intervention in the form of a safeguard, as long as the government is not better informed than the private sector.

5. In the examples above, the adjustment costs stemmed from the reallocation of labor. But one can establish similar parallelisms with the reallocation of other factors of production, such as machinery, for instance.

${ }^{9}$ Of course, if the concern is not efficiency but equity, temporary income support might be better. 
6. Very little is known empirically about the magnitude of socialadjustment costs. Economists traditionally dismiss these as being small and swamped by the gains from trade liberalization, even though it is acknowledged that they typically fall upon a few individuals, while the benefits from trade liberalization are spread over many more. Even less is known empirically about the extent to which adjustment costs depend on the speed of trade liberalization. But, for what it is worth, our intuition suggests that the speed of adjustment can indeed often importantly affect aggregate adjustment costs.

7. The reasoning above showed how social-adjustment costs might provide a rationale for social welfare-maximizing governments to include a safeguard provision in a trade agreement. But such costs should also be of concern to governments that are more sensitive to the influence of special interest groups. The weight that such a government puts on these costs may depend on who is carrying them, but the fact that the economy's productive capacity is reduced from a rapid rate of adjustment should reasonably be of concern to a broad range of government types. $^{10}$

8. We have neglected any impact that the safeguard may have on the incentives to eventually move out of the industry, by implicitly assuming away any form of strategic interaction between the private sector and the government at a later stage. In practice, firms and workers often remain in the protected industry with the rational expectation that the government will continue to adjust them also in the future. More generally, there are severe potential problems of abuse associated with safeguards, an issue to which we will return below.

\subsubsection{Safeguards and the incentive to liberalize}

The reasoning has so far identified two desirable properties of safeguards, which both contribute to enhancing the efficiency of a trade contract: in their capacity of providing escape from inflexible contract terms, they

${ }^{10}$ Are adjustment costs in the sense of reduced aggregate output necessary for governments to rationally include a safeguard provision in a trade agreement? Here we have to speculate, since we are not aware of any literature to lean against. But just as an accident involving a large number of casualties seems to attract more media and political attention than several smaller accidents combined, there also seem to exist "political adjustment costs" that depend on the speed of adjustment. For instance, large layoffs may be more costly politically than the same number of layoffs when spread over a period of time, even if the total amount of unemployment remains the same in both cases, due to more negative media coverage. If so, there would be a role for a safeguard mechanism, even without adjustment costs in the sense discussed above. 
may even, in the absence of adjustment costs that depend on the speed of adjustment, increase the efficiency of the contract after external shocks. But they also have a separate role to play: to temporarily reduce the rate of adjustment in order to reduce the total amount of adjustment costs.

But there may be a related, additional source of efficiency gains from safeguards, a source that is often emphasized in the policy debate: safeguards may induce countries to liberalize further. Consequently, the combined effect of the induced liberalization as well as the possibility of increasing tariffs ex post, may result in a fall in the average level of protection. ${ }^{11}$

Another version of this argument, more based on a public choice approach where governments are driven at least partly by motives other than social welfare maximization, is discussed by Sykes (1991). The argument here is that after trade negotiations governments may face strong pressure for protection in certain industries. A safeguard mechanism makes it possible to give in to such pressures, and thus to avoid political setbacks if participating in liberalization. As a result, governments are more prone to liberalize ex ante. While this is not a unique feature of safeguards (it is shared by other escape clause mechanisms), the potential of safeguards to avoid adjustment costs might serve as an additional motive for governments to liberalize.

\subsection{Potential drawbacks of safeguards}

We have so far painted a rather rosy picture of safeguards (and escape clauses more generally). Some of the problems (and virtues) associated with such schemes are illuminated by viewing them as insurance mechanisms, a useful but inexact analogy. ${ }^{12}$ An essential character of both trade agreements and insurance contracts is that one side in the contractual relationship may be subject to an adverse shock after the signing of the agreement. In an insurance contract there is a net transfer of resources

${ }^{11}$ Important as this effect may seem, we are not aware of any serious empirical evidence of its existence.

12 Such a perspective on safeguards is natural also from a theoretical point of view, since malfunctioning private insurance markets may serve as a basis for welfare-enhancing unilateral trade policy interventions, as demonstrated by Newbery and Stiglitz (1981), for instance. Of relevance to the issues discussed here is also the "tariffs as insurance" literature; see for instance Eaton and Grossman (1985), and Dixit (1987, 1989a, b). 
from the insurance company to the insured party. Similarly, Article XIX GATT permits a Member that is exposed to a sufficiently severe negative shock to increase a trade barrier. Formally, the Member had to provide "substantially equivalent" compensation to its trading partners, but it seems likely that trading partners will not achieve full compensation: they would have to go through a possibly lengthy and costly dispute procedure to obtain the compensation, which would serve to reduce their incentives to insist on full compensation.

The similarity between safeguards and insurance schemes does not stop here, however. Just like regular insurance contracts seek to limit the possibility of abuse through complex restrictions on their applicability, many of the features of Article XIX GATT and the Agreement on Safeguards can be seen as attempts to limit such problems. For instance, a basic problem in the case of regular insurance contracts is the conflict between risksharing and moral hazard: on the one hand, it is desirable to reduce the risk that a risk-averse party is exposed to by letting a less risk-averse party carry more of the risk. The fact that this is efficiency-enhancing (yields gains from trade), is evidenced by the insured party's willingness to pay an insurance premium to be relieved of the risk. On the other hand, the insurance may adversely affect the insured party's incentives to avoid risk it may cause a moral hazard problem.

It is easy to identify potential moral hazard problems in the context of safeguards: in particular, countries could be tempted to refrain from undertaking measures that would prepare the economy for shocks that might occur in a liberalized trade environment in the expectation of being able to rely on safeguards should a problem arise. A number of the requirements in Article XIX GATT and in the Agreement on Safeguards are naturally seen as means to limit such incentives. For instance, a safeguard can only be invoked in the case where the injury inter alia stems from increased imports. A "first-best" risk-sharing contract (the optimal contract in a situation without moral hazard problems, etc.) would not restrict the insurance to injury from increased imports. But if any domestic negative shock could to a significant extent be passed on to trading partners, the incentive for countries to pursue reasonable policies would be diminished. On the other hand, when disturbances emanate from abroad, it is less likely that they are the result of negligence or beggar-thy-neighbor behavior by the importing country. Furthermore, in order to verify that increased imports are really the source of injury, Members are required to establish a causal link between the two, just like regular insurance 
contracts require the insured party to verify any claims. Another defense against moral hazard is the requirement that the safeguard solves a problem that could not have been prevented through diligent behavior the import surge must be unforeseen.

Another generic problem facing the design of an insurance contract arises when the outcome is not perfectly observable. For instance, theft is often by its very nature hard to verify, and an insurance company largely has to trust that reported theft has actually occurred (even though it is also aided by laws against fraudulent insurance claims). When certain outcomes are not observable to the party providing the insurance, the contract needs to be designed so as to guarantee that the insured party has incentives not to over-report, or such that it is only based on circumstances that are verifiable by the insurer. A very similar problem may arise in the context of safeguards in trade agreements, where there is a need to prevent Members from claiming injury that has not occurred. In response, a country wanting to impose safeguards has to provide evidence that its industry is suffering serious injury, or imminent threat of such. Both the distribution of the burden of proof, as well as the fact that the injury must be serious, tend to ease the observability problem.

\subsection{Conclusion}

There are at least two potentially efficiency-enhancing features of escape clauses in general: they allow for ex post correction of contract terms in response to changes in external events, and they may thereby also provide incentives for further ex ante liberalization. A distinguishing feature of Article XIX GATT safeguards is that they are temporary measures that can be invoked ex post in response to external shocks. They are more quickly administered than Article XXVIII renegotiations, and they are not conditioned on a finding of dumping by foreign firms, or subsidization by foreign governments.

We have argued that there is an economic rationale for such an instrument, that is, that safeguards might enhance the efficiency of trade agreements, not only for welfare-maximizing governments, but also for governments motivated at least partly by other considerations. We can consequently meaningfully discuss a suitable implementation of this provision from an economic point of view. Had the provision instead been found to be totally undesirable from an economic perspective, it would have been difficult to discuss an economically meaningful implementation of the GATT safeguard provisions. 


\section{The legal setting}

Article XIX.1.a GATT on "Emergency Action on Imports of Particular Products" states:

If, as a result of unforeseen developments and of the effect of the obligations incurred by a Member under this Agreement, including tariff concessions, any product is being imported into the territory of that Member in such increased quantities and under such conditions as to cause or threaten serious injury to domestic producers in that territory of like or directly competitive products, the Member shall be free, in respect of such product, and to the extent and for such time as may be necessary to prevent or remedy such injury, to suspend the obligation in whole or in part or to withdraw or modify the concession.

The Agreement on Safeguards provides more details on the determination of injury, on the application of safeguards, on the causal link between imports and injury, and on a series of procedural issues. But there are some discrepancies between the Agreement on Safeguards and Article XIX GATT, and the relationship between Article XIX GATT and the Agreement on Safeguards is hence crucial for the interpretation of the safeguards mechanism. The AB addressed this issue in a couple of disputes preceding US - Lamb, concluding that safeguard measures have to be consistent with both Article XIX GATT and the Agreement on Safeguards, ${ }^{13}$ to be WTO-consistent, a position taken by the AB also in US - Lamb. We will accept this premise without further discussion.

US - Lamb concerns a safeguard measure against threat of serious injury. Article XIX GATT specifies a number of conditions for such a measure to be legal. These include that:

(i) an unforeseen

(ii) import surge has

(iii) due to obligations incurred under the Agreement

(iv) caused

(v) an unstable situation that will, absent other changes, lead to

(vi) serious injury to

(vii) a domestic industry

(viii) producing a like or directly competitive product,

(ix) and the safeguard is necessary to prevent such injury

(x) from occurring in the future.

13 The Appellate Body report on Argentina - Safeguard Measures on Imports of Footwear (WT/DS121/AB/R of December 14, 1999) reflects this approach. See $\$ \$ 83,84,93$, and 94. 
Much of the discussion in the Panel and $\mathrm{AB}$ reports in US - Lamb concerns the extent to which these conditions were fulfilled in the case at hand. In what follows, we will discuss the treatment by the $\mathrm{AB}$, in particular, of several of the conditions listed above.

The Preamble of the Agreement on Safeguards contains the following passage:

Recognizing the importance of structural adjustment and the need to enhance rather than limit competition in international markets...

(emphasis added)

The Preamble is of limited legal value. Article 2 SGA, which lays out the conditions for a lawful imposition of safeguards, does not include a reference to structural adjustments. Consequently, although WTO Members do not have the binding legal obligation to undertake structural adjustment whenever they have recourse to a safeguard, the Agreement expresses a wish that this be the case.

\section{4 “... unforeseen developments ..."}

Article XIX.1.a GATT stipulates that the safeguard measure must be taken in response to "unforeseen developments." There was dispute as to whether the unforeseen requirement had survived into the WTO era, since this requirement is not explicitly mentioned in the WTO Safeguards Agreement, contrary to Article XIX GATT. In its report on Argentina Footwear $(E C)$, the $\mathrm{AB}$ held the view that, by virtue of the explicit link to Article XIX GATT in Article 1 SGA, WTO Members cannot lawfully impose safeguards unless they satisfy the unforeseen requirement as well. ${ }^{14}$ US - Lamb is the first dispute where a WTO Member's allegation that an event was unforeseen has been rejected by the $A B$. A purely descriptive

${ }^{14} \mathrm{WT} / \mathrm{DS} 121 / \mathrm{AB} / \mathrm{R}$ of December 14, 1999. The legal correctness of this approach is dubious. It seems that the AB confused two different issues: Article 1 SGA is entitled "General Provision" and refers to Article XIX GATT explicitly only to describe which measures should be understood to be safeguard measures. Article 2 SGA, which is entitled "Conditions," by contrast mentions the legal requirements that have to be fulfilled for a safeguard measure to conform to the SGA. Article 2 does not mention at all the unforeseen developments requirement. The $\mathrm{AB}$ imported into Article 2 SGA a requirement which does not exist. Article 1 SGA, as its title and accompanying text indicates, was not intended to discuss the conditions for lawful imposition of safeguards. It was meant to describe what form a safeguard measure can take. Unfortunately, in the present case, the AB followed this case law, which seems to lack legal merit. 
statement, which does not explain the reasons why developments were unforeseen, does not suffice in the view of the AB. ${ }^{15}$

\subsection{Implications of the notion of "unforeseen"}

\subsubsection{Unforeseen means "unlikely" and not "unforeseeable"}

Leaning against the $\mathrm{AB}$ report in Korea - Dairy, the panel argued that "unforeseen" should not be interpreted as "unforeseeable." Unforeseeable events are by necessity unforeseen, but unforeseen events

... may nevertheless be foreseeable or predictable in the theoretical sense of capable of being anticipated from a general scientific perspective ...

We concur with this interpretation. As we understand this statement, it distinguishes between what is unlikely and what can not be conceptualized. For instance, taking imports as an exogenous factor, what matters to domestic producers is the supply of imports, the volumes and/or prices at which imports are supplied. If the import volume a certain year is 100 , it might appear very unlikely that it will next year be 200, and an occurrence of such a high volume might be "unforeseen" in the sense of "surprising." However, it is a different matter to say that an import volume of 200 is unforeseeable in the sense that producers could not conceptualize such a volume. The latter would clearly be an unreasonable criterion. It can also be noted that the interpretation of "unforeseen" as "unforeseeable" in this sense does not sit well with the argument that the safeguard mechanism makes Members more willing to liberalize.

An important question in practice is of course how unlikely a development should be to allow for a safeguard. Neither Article XIX GATT, nor the Agreement on Safeguards, gives any guidance on this. It is also not possible in practice to lay down rules in terms of probabilities. But given the incentive problems associated with this type of instrument, we would argue that the reasonably perceived probability for a negative shock to the domestic industry must have been very low, for a safeguard to be allowed, if serious injury were to materialize.

${ }^{15}$ It appears as if in GATT 1994 "unforeseen" is only used once in the Agreement on Import Licensing Procedures, and once in the Understanding on Dispute Settlement. Neither case seems to provide any light on its intended interpretation. 
4.1.2 Unforeseen implies "not being the deliberate cause of" The interpretation of unforeseen as unexpected has another desirable consequence: it implies that safeguards cannot be employed in situations where the problems are caused by willful mismanagement or neglect by the government, to the extent that the serious injury should reasonably be expected from this type of behavior. Unforeseen thus also seems to imply "not being the deliberate cause of."

This implication of "unforeseen" has in turn important ramifications for the notion of "increased imports" as a necessary condition for a safeguard. An import surge can be caused by the country seeking to impose safeguards simply by an internal measure that reduces domestic supply, or increases domestic demand. From an economic point of view, it is natural to argue that the government should understand this consequence of the internal measure, and that there would be no ground for a safeguard in such a case.

How detailed an understanding of the economy should the government then be required to have? After all, the economic system is extremely complex - this complexity is indeed what economists make a living on - and a policy intervention somewhere in the economy might have consequences very "far" away in the system that are practically impossible to predict. The link between the policy measure and these developments can in a certain sense be said to be "unforeseeable." The question is then whether the inability of the government to understand how a certain action affects the economy is a sufficient ground to classify the resulting developments as "unforeseen."

In our view, one cannot demand of governments to be able to foresee all economic consequences of their actions. It also seems reasonable that serious injury that is caused by the importing government's interventions for clearly different purposes should not necessarily be disqualified as a ground for safeguards. But governments should obviously be expected to have a "reasonable" understanding of the working of the economy. It is not possible to specify exactly what can and what cannot be foreseen in this sense - this has to be left to the discretion of the adjudicating bodies in each separate case. But the government should be able to demonstrate that it could not reasonably have expected the import surge to result from its policy intervention, in order to legally impose a safeguard. That is, there should be a "due diligence" standard to be respected by national administrations. At any rate, safeguard measures imposed by a government after it has knowingly provoked an 
import surge should be considered as inconsistent with the Agreement on Safeguards.

One might take the argument even further, however, and include the behavior of the private sector. For instance, governments do not normally know the details of specific industries, but have to rely on the industry to warn them of future problems. What if an industry does not spend enough efforts on forecasting future developments due to mismanagement? Or, what if the industry allows for wage hikes that it cannot afford without protection? Maybe the industry has strategically put itself in the adverse situation in the rational expectation that it would be bailed out through safeguards if a problem were to arise. More generally, should serious injury caused by "reckless" behavior by the private sector be a legitimate ground for a safeguard? If so, will not this induce moral-hazard-like problems, whereby protectionist-minded governments tacitly encourage this type of behavior on the part of the industry? ${ }^{16}$

This discussion of the appropriate restriction on the applicability of safeguards has been pursued from a strictly economic perspective. It suggests that safeguards should not be permitted in response to private-sector reckless behavior, since this would invite moral-hazard problems. But from a legal perspective, for a WTO Member to be liable, there must be an active behavior attributable to the Member. It would therefore be difficult to make the legality of the measure dependent on the behavior of the private sector, unless, following the ruling in Japan - Trade in Semiconductors dispute, ${ }^{17}$ the government has actively induced the private sector behavior. There thus here seems to be conflict between the principles of economics and of law.

16 The problems that arise in this context are similar to those discussed in macroeconomics concerning the use of government policies to counter cyclical variations in economic activity. Much of the discussion there has focused on the possibility that the private sector learns to see through the government's incentives to intervene. For instance, the expectation by the private sector that the government will accommodate rising unemployment through inflationary monetary policy, may induce the private sector to show less restraint to wage increases, thus causing unemployment that will trigger expansionary monetary policy. The government's control of the money supply - this is the counterpart of its access to a "safeguard mechanism" - thus creates a situation where it is forced to increase money supply, the end result being higher inflation but the same level of, say, unemployment. One of the main reasons why the control of money supply increasingly is delegated to independent central banks is precisely to avoid these problems. One should think that there should be a lesson to learn from this also for safeguard mechanisms in trade agreements.

17 Japan - Trade in Semiconductors, (GATT Doc. BISD 35S/116 of May 4, 1988). 


\subsection{When should the event have been unforeseen?}

Yet another issue in this context is the time at which the import surge should have been unforeseen. ${ }^{18}$ Neither Article XIX GATT, nor the Agreement on Safeguards, gives any guidance on this issue. There seem to be at least two natural possibilities here. One is to interpret the contract date as the time at which the external event must have been foreseen. Clearly, if the parties could foresee the future change at the time of signing the trade agreement, a safeguard could hardly be motivated.

The opposite situation, where the change is not foreseen at this date, is more problematic. A trade agreement such as the Uruguay Round may regulate trade for a number of years. Clearly, the longer the period between agreements, the more likely that unforeseen developments will occur. Therefore, some events occurring after the signing of the agreement could qualify as unforeseen developments. Then, could any event occurring after the signing of the contract serve as a basis for a safeguard? We would argue no.

To illustrate, consider the example discussed above with the declining lamb-meat industry. In this example, had the government known one quarter (or longer) before that an import surge was forthcoming, it could have induced 6,000 workers to leave the industry during this quarter, and let the rest leave the first quarter after, thus making the safeguard unnecessary. The legality of a safeguard in this case would thus depend on whether a due diligence standard would require the government to have foreseen the shock to come the quarter before. More generally, for the safeguard to be legal it should hence be required that the cause of the serious injury could not reasonably be foreseen at a time when action was necessary in order to avoid it.

\subsection{How to establish what was unforeseen}

As argued above, the essential feature of an unforeseen development must be that the government reasonably attributed a low probability to it occurring, and that it then nevertheless materialized. It is not a trivial exercise to empirically determine such probabilities. Of course, it does not suffice to establish the occurrence of a sharp increase in imports, since it may

18 This question is not to be confused with the issue of whether the occurrence of previously unexpected events has to be established publicly as part of the investigation before the safeguards are invoked. 
have been well understood at the time of signing the agreement that such developments would take place, perhaps even as a result of the agreement.

The existence of the safeguard regime itself adds further complexity to the practical determination of whether events were reasonably unexpected or not. For instance, a tempting possibility would be to use stock prices, the idea being that the stock market could be a suitable indicator of what can be reasonably expected. If stock prices did not deteriorate until the import surge actually set in, the surge might be argued to be unexpected. The problem with this approach, however, is that the scenario where the lack of reaction in stock prices motivates safeguards, might not be distinguishable from the one where the stock market actually foresees the import surge, but in the expectation of safeguards does not alter its valuation of firms in the industry to any noticeable degree.

Consequently, it seems clear that it might be very difficult for a country wanting to impose safeguards to verify in a more scientific fashion that an import surge was unexpected given a due diligence standard. We nevertheless believe that Members seeking to impose safeguards should be requested to provide some statistical verification of the claim that an unlikely situation has arisen, given the information at hand. Such an exercise can on few occasions decisively determine whether the unforeseen criterion has been established, but might serve to add some rigor to an otherwise very "soft" test. The importing country would then need to explain why it cannot statistically support its claim, if this is the case. At the end of the day, however, it seems difficult to avoid having to rely on a discretionary judgment concerning whether the developments were unforeseen or not.

\subsection{An awkward feature of safeguard investigations}

There is a somewhat awkward aspect of the safeguard mechanism with regard to the "unforeseen developments" criterion. The essence of such an investigation is that a government agency evaluates whether past mistakes by itself, or possibly some other agency, in forecasting industry developments, were indeed acceptable despite a due diligence standard. Only when the agency behaved correctly when making the forecast mistake can a safeguard be permitted. This somewhat odd arrangement makes it all the more important that the adjudicating bodies in the WTO maintain clear standards for what is acceptable and not as a basis for a safeguard. 
4.5 Were "unforeseen developments" established in US - Lamb?

The US argued in US - Lamb that there is no legal obligation for the USITC to include in the published report an examination of whether the developments were unforeseen, since this can be done if a dispute arises. The $\mathrm{AB}$ did not accept this reasoning, and ruled that a demonstration of unforeseen developments must be made prior to the application of the safeguard.

The US also claimed that the change in the product mix of imports as well as an increase in the cut size of imported lamb factually constituted unforeseen developments, and that these developments were documented in its report. The Complainants did not contest the existence of these changes, but maintained that they were largely the consequence of the removal of subsidies under the Wool Act, and that these consequences could and should have been foreseen.

In the Panel's view, the US only provided descriptive statements of the import surge, and did not establish as a matter of fact that they were really unforeseen:

... it is our view that these USITC statements concerning the change in product mix or the increase in cut size, on their face, are simple descriptive statements, and cannot be construed as a conclusion as to the existence of "unforeseen developments" in the sense of GATT Article XIX:1.

The AB basically upheld this view, stating that

... we see no indication in the USITC report that the USITC addressed the issue of "unforeseen developments" at all ...

... even though the $\mathrm{AB}$ also said that it did not agree with every aspect of the panel's reasoning. It is not clear to us, however, what exactly they did not agree with.

We share the adjudicating bodies' view that the US did not convincingly demonstrate that the developments motivating the safeguard were unforeseen, and we believe that such a demonstration should be an integral part of the safeguard investigation. As far as we can see, there is nothing that would prevent the use of some form of econometric/statistical analysis in a case like US - Lamb. As mentioned above, such analysis might not be decisive, but should serve to provide much better ground for a judgment; we will return to this issue in the last section. More generally, we see the 
adjudicating bodies' rejection of the US International Trade Commission methodology as a welcome strengthening of the burden of proof required to demonstrate that a safeguard was imposed as a response to unforeseen developments.

\section{5 “... causal link between increased imports ... and serious injury or threat thereof..."}

Article 4.2(b) SGA requires

... the existence of the causal link between increased imports of the product concerned and serious injury or threat thereof. ...

It further specifies that

[w] hen factors other than increased imports are causing injury to the domestic industry at the same time, such injury shall not be attributed to increased imports.

As discussed above, these requirements are natural components in the attempt to prevent abuse of the Agreement on Safeguards. But they give rise to rather severe problems of interpretation and implementation, also leaving aside the general philosophical problem of the meaning of the term causality. We will in this section touch upon some of these problems. Most of the discussion will concern increased imports as a cause of actual injury, rather than a threat thereof. The issues involved are in any event rather intricate, and the former is conceptually simpler than the latter. An understanding of the former also seems to be a necessary step toward an understanding of the latter.

\subsection{The definition of "serious injury"}

The appropriate interpretation of the term "serious injury" depends on the objectives of the Member governments. A government that is only concerned with aggregate social welfare might care about aggregate adjustment costs caused by too rapid adjustment to external shocks, and use these costs to measure injury. A government that is more concerned with the situation of particular politically influential groups might judge injury from reductions in the level of production in specific sectors, reduced profitability or financial viability of specific domestic industries, unemployment spells of a significant duration, etc. 
Except for a mundane, almost tautological definition of "serious injury" in Article 4.1a SGA,

... "serious injury" shall be understood to mean a significant overall impairment in the position of a domestic industry...,

the term is not defined in this agreement. For instance, contrary to what is the case in the Anti-dumping or Subsidies Agreements, the Agreement on Safeguards does not contain a de minimis standard for import surges (although, a priori the term "such increased quantities" seems to address this issue). More problematic is the absence of de minimis standards when it comes to injury. It is yet unknown as a matter of WTO positive case law whether a claim by a socially conscious State that laying off a minute percentage of the workforce in a particular field passes the "serious injury" test.

We will not delve into any more elaborate discussion of possible interpretations of "serious injury." The particular choice of measure does not seem to matter for the discussion to follow, as long as it is strictly correlated with domestic production, which we take to be inversely related to injury.

\subsection{The choice of explanatory variables}

The method typically employed in economics to establish "causality" is to combine a theory for (an understanding of) how the variables are related, with econometric use of actual observations. The theory distinguishes between endogenous and exogenous variables. Endogenous variables are those whose magnitudes are determined within the theory; typical examples are price levels, and levels of production and consumption. The values of the exogenous, or explanatory, variables, on the other hand, are not determined within the theory but are imposed on the analysis. For instance, the standard demand and supply model of a specific market would assume that consumers' incomes influence demand, but would treat these incomes as determined by forces outside the analysis.

More generally, the aim of the theory is to highlight how the exogenous factors contribute to determining the endogenous variables of interest. The theory in this sense predicts how exogenous factors cause a particular situation. Clearly, the predictive power of such a theory depends crucially on the choice of exogenous variables. The theory must include all those variables that in actuality are important, since the econometric estimation of the theoretical relationships may otherwise be biased, and thus not 
trustworthy. For instance, the estimation may exaggerate the contribution to injury of the factors included in the analysis.

\section{3 "Increased imports" as cause of injury}

Both Article XIX GATT and the Agreement on Safeguards require that unforeseen developments have induced an increase in imports which has led to (or threatens to lead to) serious injury, for a safeguard to be legal. This criterion is problematic from an economic point of view: hardly any economic theory would view the volume of imports as an exogenous variable determining, say, domestic employment, or some other indicator of serious injury. Almost any theory would view imports as determined simultaneously with domestic employment, and determined by factors that are at least in the shorter run exogenously given to the industry.

If the object of study were imports in a particular industry, exogenous factors included in the analysis would typically be consumer incomes, prices of other products, prices of productive factors, etc. This would be a "partial equilibrium" analysis. If the focus instead were on aggregate imports, the exogenous factors would include consumer preferences, production technologies, national endowments of productive factors, etc.; this would be a "general equilibrium" analysis in which all relevant prices are determined within the model.

It is in our view central to the interpretation of the safeguard provisions in the WTO to see imports as determined simultaneously with domestic variables, such as production and employment. At the risk of offending those with their Economics 101 in fresh memory, but as a service to those who found it useful to reserve this memory slot for other matters, we will therefore in the next subsection lay out a very basic economic analysis of how imports in a particular industry are determined simultaneously with variables closely related to injury.

Generally speaking, imports can be seen as the outcome of the interaction between supply and demand in the importing country, and in the rest of the world. To see how, consider figure 4.1. The right-hand side depicts demand and supply for the product in the domestic economy. At any price less than the price indicated by " $a$," the demand for the product is larger than what the domestic industry is willing to supply, and for these prices there will be a demand for imports. This demand is illustrated by the downward-sloping curve on the left-hand side. Import demand is thus simply derived by subtracting domestic supply from domestic demand. The position and slope of this curve depends on factors that will be treated 


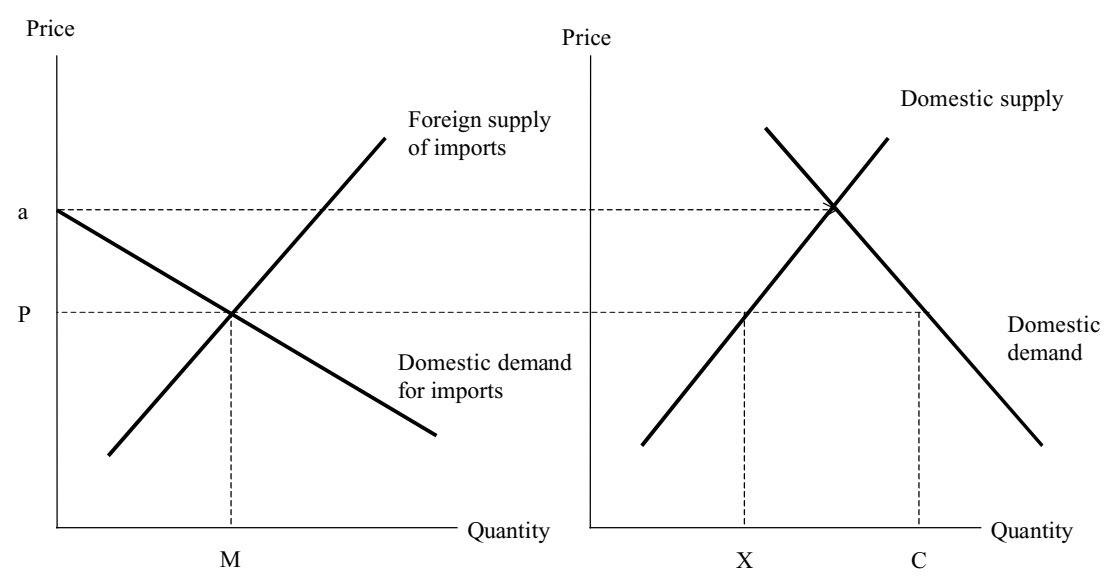

Figure 4.1

as exogenous to the analysis, but that we still might want to include in the analysis, such as domestic income levels, prices of substitute products, and the local cost of production.

In exactly the same fashion one can derive the net behavior of the rest of the world, by subtracting from its supply the volume demanded in the foreign country, for each price. The resulting curve, depicted as the upward-sloping supply curve on the left-hand side of figure 4.1 , shows the supply of the import good from the rest of the world at any given price. The imported volume $\mathrm{M}$, as well as the price of the product, is then given by the intersection of the import demand and supply schedules. Having thus established the equilibrium price, the domestic production volume $\mathrm{X}$ and the domestic consumption, volume $\mathrm{C}$ can be determined on the righthand side of figure 4.1 .

This very simple model illustrates two general points. First, the level of imports is determined simultaneously with the price at which trade occurs, and thus also with the amount supplied by the domestic industry. Hence, we might equally well say that domestic production (or some other indicator of injury) causes a certain import volume, as say that imports cause a certain level of domestic production (injury). Consequently, it is not meaningful to view "increased import" as an exogenous event, since it must be seen as being caused by changes in the underlying determinants of imports, some domestically determined, others determined in the rest of the world.

Second, we have to distinguish between increased imports that result from a movement along the supply curve of imports and increased imports 
due to a shift in this curve. A movement along the import supply curve would occur if only the import demand curve shifted. For instance, a removal of a production subsidy to the domestic industry would reduce domestic supply at any given price, and thus increase the domestic demand for imports. The new equilibrium would then be given at a new intersection point along the import supply curve, and would feature an increased volume of imports. On the other hand, the import supply curve would shift if factors determining import were to change. As an example, reduced consumer income abroad would increase foreign export supply, and thus shift the import supply curve to the right. The consequence would again be an increased volume of imports.

The reason why a movement along the import supply curve needs to be distinguished from a shift in this curve is that both changes would give rise to an increased import volume, and reduced domestic production. The two scenarios thus appear equivalent in this sense. However, the reasons behind the changes are very different. In the first case they stem from changes in the domestic economy, and in the latter from disturbances emanating from abroad.

\subsection{When is a change in imports a legitimate ground for a safeguard?}

Let us now return to safeguards. As illustrated by the simple framework laid out above, increased imports is not an exogenous development, but the result of more fundamental changes, affecting import demand and/or supply. A fundamental issue when implementing a safeguard regime is therefore the type of disturbances that could serve as legitimate grounds for safeguards. Several fundamentally different approaches may be adopted.

A highly permissible standard would be to treat anyincrease in imports, irrespective of the source of the underlying development, as a legitimate ground for a safeguard, provided it is associated with serious injury. This criterion would thus allow not only disturbances emanating from abroad as legitimate grounds, but also those stemming from domestic sources. To see one way in which the effect of increased imports could be disentangled from the direct effect of the cost shock, consider a numerical example. ${ }^{19}$

Suppose that a domestic industry initially produces 10 units, 12 units are imported, and the equilibrium price is 20 ; this situation is illustrated in

19 A more general exposition of this line of reasoning can be found in Pindyck and Rotemberg (1987). 


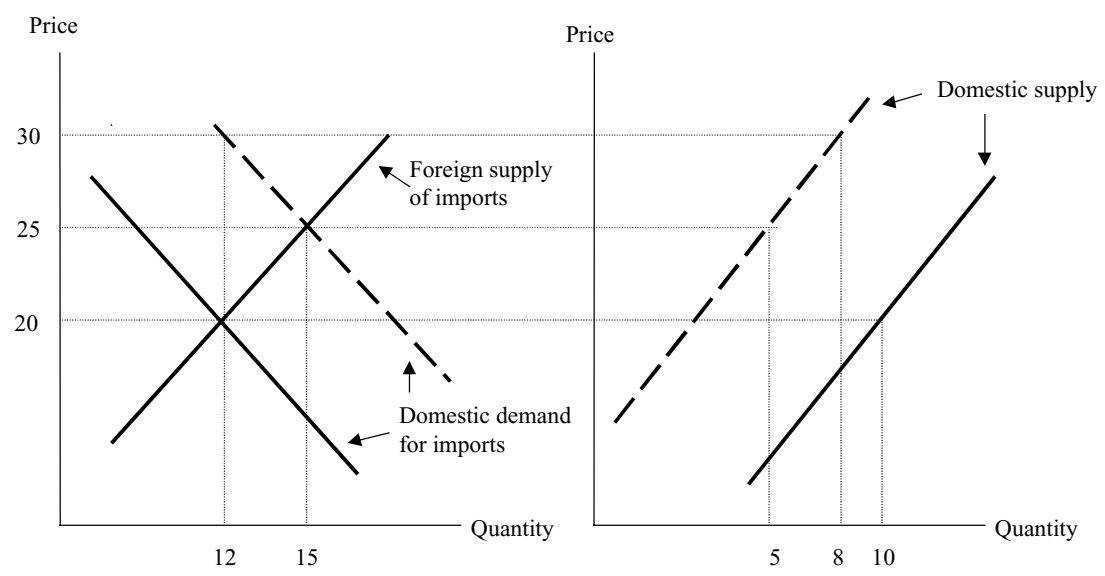

Figure 4.2

figure 4.2. The domestic industry is then hit by an adverse cost shock; this is graphically illustrated by a shift of the domestic import demand to the right (more of domestic demand is directed toward imports) in the panel on the right, and an inward shift of the domestic supply in the other panel. Now, if imports were somehow to remain at 12 units, the price would increase to 30 , and local production would fall to 8 units. The resulting injury from this reduction in output would not be a valid reason for a safeguard. However, the higher price induced by the reduced supply will stimulate supply of imports, and in the new equilibrium where the price equals 25 , imports will have increased to 15 , and domestic production fallen to 5 . The fall in domestic production from 8 to 5 induced by the increase in imports would then serve as a basis for a safeguard. Hence, according to this criterion, a safeguard could be invoked even though the source of the injury is a domestic shock, but only to the extent that imports "take advantage" of the domestic cost shock.

Consider next a substantially stricter standard. As discussed above, the "unforeseen" criterion can reasonably be interpreted to imply "not being the deliberate cause of." This could be required also with the above more permissible standard, in which case a domestic cost shock could serve as a basis for a safeguard only when it is not caused by the importing country. However, due to the moral hazard-type problems associated with safeguards, it might be argued that safeguards should be reserved for situations where the source of the disturbance is foreign. This would also solve the problem of reckless behavior by domestic private parties. In terms 
of the analytical framework above, this would amount to a requirement that the shock originates from the foreign import supply, rather than import demand, in order to be a legitimate basis for a safeguard. For instance, an increase in foreign productivity, which would increase the net supply of imports, would be a sufficient reason, while a deterioration of domestic productivity that leads to a higher level of imports through increased import demand, would not qualify.

In our opinion, the possibilities of abuse of the safeguard instrument suggest that the stricter criterion is preferable. ${ }^{20}$

\subsection{Methods for attributing injury}

If one knew with certainty that the shock to the system had a unique origin, and felt comfortable with the representation of the industry given in the simple framework laid out below, one could deduce whether import demand or supply had changed. In the former case the increase in imports would be associated with an increase in the price, while in the latter case there would be a fall in the price. In practice, however, several disturbances are likely to interact, simultaneously contributing to injury. This fact is acknowledged by the Agreement on Safeguards, which requires that injury shall not be attributed to imports to the extent it has other sources. In order to achieve this, the analysis thus disentangles the various sources of injury.

We will not delve into any more detailed discussion of appropriate econometric/statistical methods for empirically attributing injury - this is a far too complex issue to be addressed in a few paragraphs. Broadly speaking, the literature suggests two possible approaches to the attribution of injury. One is to econometrically estimate the relationship between injury and various possible explanatory variables, using observations on prices, imports, production, etc. The other approach is to use information

${ }^{20}$ In the US, safeguards are administered under Section 201 of the 1974 Trade Act. Interestingly, Kelly points out that the legislative history of the Act suggests that domestically induced disturbances were not meant to be legitimate grounds for safeguards in the US:

The existence of any of these factors such as the growth in inventory would not in itself be relevant to the threat of injury from imports if it resulted from conditions unrelated to imports. Such conditions could arise from a variety of other causes, such as changes in technology or in consumer tastes, domestic competition from substitute products, plant obsolescence, or poor management.

Senate Report, 1298, 93 Cong., 2nd Session, 20 (1974). Kelly (1988) adds that "[a]ll these other causes can be characterized as shifts in either the demand or the domestic supply curves." 
on demand and supply elasticities, and on changes in injury, to back out what exogenous changes that might have caused the observed injury. We will very superficially describe these below, just to give a feeling for how they work.

\subsubsection{Econometric attribution analysis}

In order to give some flavor of one way an econometric attribution analysis can be done empirically, we will very briefly describe the approach taken by Grossman (1986), who analyzed whether the alleged injury to the US steel industry in the early 1980s in terms of reduced employment, was due to international disturbances, or to domestic factors. ${ }^{21}$

The study is based on a theoretical model that in an important sense is simpler than the model sketched above: whereas in the model above there was an upward sloping supply curve for exports, Grossman assumes that exporters are willing to serve the whole domestic market at a price above a certain threshold, and not serve at all below this value. Graphically, the export supply is thus a horizontal line. ${ }^{22}$ This may correspond to a situation where the domestic market is small relative to the world market. Grossman derives an equation that shows how the endogenous variable, domestic employment, depends on the exogenous variables such as prices of various inputs including labor, aggregate production in the US, and the price of imports. ${ }^{23}$

In order to assess the empirical magnitudes of these different influences, Grossman (1986) econometrically estimates the model, using actual data on the endogenous and exogenous variables. The resulting estimated parameters indicate the impact of each of the exogenous factors on employment. These estimates thus summarize the "average" contribution of each of the exogenous factors to employment during the period under consideration.

In order to verify a claim that an import surge has caused serious injury, it does not suffice to look at average relationships, of course. It must be shown that the particular instance of alleged serious injury at stake is caused by the factors that determine imports. That is, it must be shown that the injury would not have arisen, had the alleged development not

21 For an alternative approach, see Pindyck and Rotemberg (1987).

22 By assuming an infinitely elastic supply of imports, Grossman avoids some of the problems discussed above, with the simultaneous determination of import prices, and domestic injury, and can therefore treat the import price as an exogenous variable.

23 The model is more sophisticated than described here. For instance, it also includes a version where the wage rate is determined endogenously, as well as time trends for various variables. 
occurred. In order to investigate this, Grossman (1986) uses the estimated parameter values for counterfactual simulations.

For instance, when assessing the importance of the development of the price of imports for employment, Grossman computes the counterfactual path that the estimated model predicts employment would have followed, had the price of imports remained at the level it had in the early phase of the period, while all other explanatory variables followed their actual paths. By comparing this simulated path for employment with its actual path, one obtains a measure of the contribution of the development of the import price to employment. Similarly, one can simulate the importance of each of the other exogenous factors. Finally, comparing the outcomes of these different experiments, one can derive a measure of the degree to which the import-related variables contribute to the employment development.

It can be argued that this method does not establish more than correlation, being essentially static in its nature. However, Grossman (1986) actually uses a dynamic specification of the model, where delays in the response to exogenous disturbances are taken into account. In this richer model, it is possible to examine whether certain changes in exogenous variables precede changes in the level of injury. Such a pattern is usually taken as a requirement for causality to be shown. ${ }^{24}$ But we would argue that a pure correlation analysis might also be informative. As mentioned above, if a correlation between the injury measure and (in this case) imports cannot be found, a causal relationship seems highly unlikely.

\subsection{2 "Injury accounting"}

The virtue of the econometric estimation approach is that it can give a detailed understanding of the determinants of injury. But it can often be demanding in terms of data requirements, and it might require a rather sophisticated econometric analysis, in particular when it involves the simultaneous estimation of several equations (such as separate supply and demand relationships).

An alternative approach is proposed by Kelly (1988), and is supported by Irwin (2002). The attractiveness of this approach is that it only requires data that are normally available in safeguard investigations. It builds on the simple supply and demand analysis laid out in figures 4.1 and 4.2 above. Using this model, one can easily derive the predicted relationships between the measure of injury (domestic production) and the exogenous factors

24 One event preceding another related event is not enough for there to be a causality, as the well-known Christmas card example shows: these cards appear before Christmas, and can thus in a statistical sense be shown to "cause" Christmas. 
determining import supply and domestic demand. These relationships will depend on demand and supply elasticities, as well as on changes in domestic demand and imports.

One can then decompose the reduction in domestic production in terms of changes in the other variables, given the elasticities. Hence, in a sense the method reverses what normally are the endogenous and the exogenous variables, by asking "given the observed elasticities, how much must the exogenous variables have changed in order to get the changes in the endogenous variable that are actually observed?" These computed changes in imports, and other factors/variables are then compared with actually observed changes. If there is a significant discrepancy between the estimated and the observed variables, the alleged causality from import changes to injury would not seem very plausible.

\subsection{Imports as cause of injury threat in US - Lamb}

A central issue in the dispute is whether the investigation by the US International Trade Commission adequately attributed the threat of serious injury to imports and to other factors. The procedure employed by the Commission was to identify six factors in addition to imports that might have caused injury, and then to ask whether each of these factors individually was more important than increased imports. The Commission found this not to be the case, and hence concluded that increased imports were an important factor threatening injury, and that it was no less important than any other factor. The complainants argued that the US International Trade Commission investigation failed to show the aggregate effects of factors other than increased imports, and that it did not demonstrate a "genuine and substantial relationship" between imports and the injury threat.

According to the Panel, the fact that the threatened injury has to be serious, suggests that

... increased imports must not only be necessary, but also sufficient to cause or threaten a degree of injury that is "serious" enough to constitute a significant overall impairment in the situation of the domestic industry. We also note that there is a difference between a sole cause, on the one hand, and a necessary and sufficient cause, on the other. Any sole cause is by definition a necessary and sufficient cause, but obviously not any necessary and sufficient cause is the sole cause, it may coincide with other causes as recognised by the second sentence of SG Article 4.2(b). 
... increased imports need not be the sole or exclusive causal factor present in a situation of serious injury or threat thereof, as the requirement not to attribute injury caused by other factors by implication recognises that multiple factors may be present in a situation of serious injury or threat thereof.

... where a number of factors, one of which is increased imports, are sufficient collectively to cause a significant overall impairment of the position of the domestic industry, but increased imports alone are not causing injury that achieves the threshold of "seriousness" ... the conditions for imposing a safeguard measure are not satisfied ... we cannot see how a causation standard that does not examine whether increased imports are both a necessary and sufficient cause for serious injury or threat thereof would ensure that injury caused by factors other than increased imports is not attributed to those imports.

In support of its views, the US - Lamb panel referred to the panel report on US - Wheat Gluten, ${ }^{25}$ which was on appeal at the time of the writing of the US - Lamb report. The findings on causality in this report were later reversed by the $\mathrm{AB}$.

The AB refers in US - Lamb to its findings in US - Wheat Gluten, and the $\mathrm{AB}$ reverses the US - Lamb Panel's causation requirements, arguing that the Agreement on Safeguards

... does not require that increased imports be "sufficient" to cause, or threaten to cause, serious injury. Nor does that Agreement require that increased imports "alone" be capable of causing, or threatening to cause, serious injury.

The $\mathrm{AB}$ still finds fault with the US methodology, however, but on different grounds than the Panel. It first states that the Agreement on Safeguards obliges WTO Members wishing to impose a safeguard measure to determine "whether there is a genuine and substantial relationship of cause and effect between increased imports and serious injury or threat thereof" (179). It further states that Communities. WT/DS166/AB/R. December 11, 2000. 
[i]n a situation where several factors are causing injury "at the same time," a final determination about injurious effects caused by increased imports can only be made if the injurious effects caused by all the different causal factors are distinguished and separated.

Hence, in the AB's eyes, the US were wrong not because increased imports must be a sufficient cause for injury but rather because the US did not distinguish the effects of factors other than increased imports from the effects that increased imports had on the domestic lamb industry. The AB thus upholds the Panel's conclusion that the US acted inconsistently with the requirement in Article 4.2(b) SGA to show causality between increased imports and the threat of serious injury.

We agree with the $A B$ that the US International Trade Commission attribution analysis was insufficient, due to its methodological deficiencies. As also noted by Irwin (2002), the ruling seems simply based on assertions, and lacks quantitative analysis. An indication in support of the adjudicating bodies' determination that imports had not been shown to cause injury, is Irwin's (2002) observation that in US - Lamb, there were simultaneous increases in domestic and import prices and imports, and reductions in domestic consumption and production. These changes are inconsistent with the claim that the dominant effect behind the injury was an increase in import supply, since such an increase would reduce prices in general. Hence, the explanations must instead be sought on the import demand side. Here, reduced domestic demand would not do the trick, since this would not give rise to a price increase. However, reduced domestic supply would give rise to the type of pattern observed. Indeed, the removal of the US Wool Act subsidies that preceded the alleged injury would have had such an effect.

Irwin (2002) also employs the approach proposed by Kelly (1988) to investigate the determinants of reduced domestic output in a number of US safeguard decisions. For the case of US - Lamb, Irwin (2002) again finds that the reduction in domestic production resulted from an inward shift in the domestic supply schedule.

While we agree with the AB's dismissal of the USITC's analysis, we find it unsatisfactory that the $\mathrm{AB}$ does not explain how a satisfactory analysis is to be done. In order to improve the methods employed by national administrations in safeguard analyses, we would like to see the $\mathrm{AB}$ provide some indication to the Members as to how a more thorough quantitative analysis than what is currently being undertaken could be performed. 


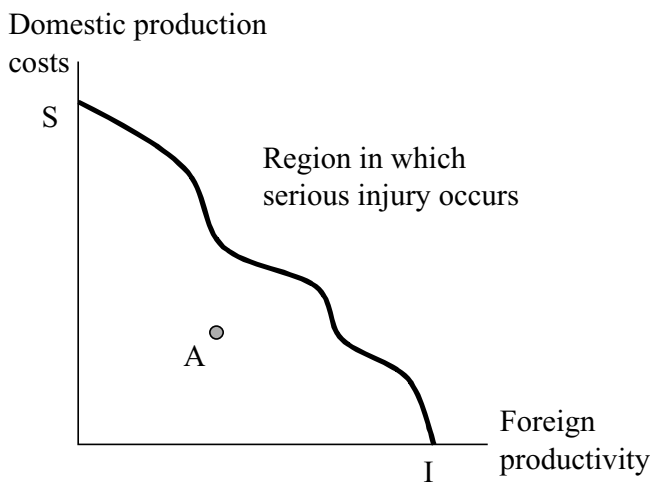

Figure 4.3

\subsubsection{Differences in the criteria employed by the US International}

Trade Commission, the Panel and the AB to determine the legitimacy of safeguards

A situation of serious injury might arise both due to domestic reasons and to reasons clearly beyond the control of the domestic government. The Commission, the Panel and the $\mathrm{AB}$ seem to use different criteria for how to weigh the contributions of such internal and external sources. In order to shed some light on differences in these approaches, we will use a simple example where serious injury can result from two developments: increased foreign productivity, and increased costs of domestic production. The former is taken to be a legitimate ground for a safeguard, but not the latter. Thus, in line with the reasoning above we do not view imports as an exogenous factor, even though this analysis might also have been conducted in terms of imports and some external factor.

More importantly, we will assume that the foreign productivity and domestic production costs most of the time take on their "normal" values. But in rare occasions they may increase and possibly cause serious injury. The "normal" value thus serves as a reference point against which deviations in domestic costs and foreign productivity are measured.

The model is graphically illustrated in figure 4.3 , which measures foreign productivity on the horizontal axis, and domestic production costs on the vertical axis. Point "A" represents the "normal" value of these exogenous variables. The downward sloping curve "S-I" depicts combinations of foreign productivity and domestic production costs that are sufficiently severe to give rise to "serious injury" according to some agreed-upon criterion. Hence, at any point on this curve or to the "north-east" of it, the industry is experiencing serious injury. This curve is naturally downward 


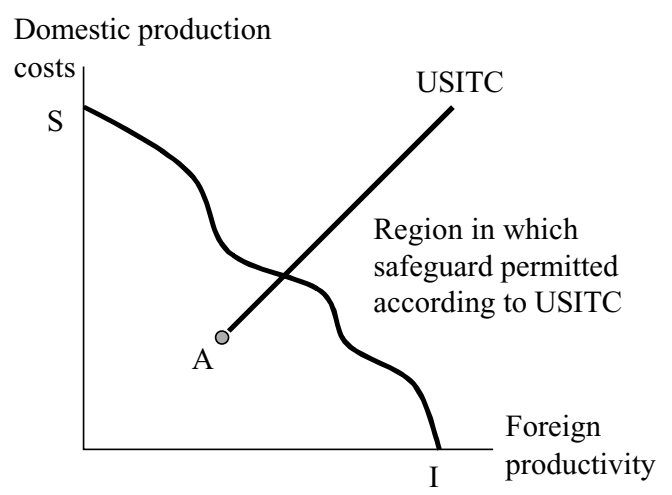

Figure 4.4

sloping, since higher foreign productivity would typically require lower domestic production costs in order for the injury level to remain constant.

We will now try to interpret the criteria employed by the US International Trade Commission, the panel and the $\mathrm{AB}$ to determine whether a particular realization of foreign productivity and domestic production costs suffices as a basis for a safeguard. The exposition will be somewhat speculative, in that it rests on our understanding of the different approaches, and we do not always fully understand exactly what is meant. Hopefully, however, the analysis captures salient features of the various criteria, and at the very least demonstrates the virtue of a more formal approach in that it forces a clearer, more explicit statement of the assumptions underlying the analysis. ${ }^{26}$

Let us start with the Commission approach. We interpret it to say that a safeguard is justified if a foreign productivity increase is a more important factor contributing to injury than an increase in domestic production costs, but where the serious injury criterion is evaluated by considering the combined effect. Taking the "normal" values of domestic production costs, and of foreign productivity, as a point of reference, there are thus according to this reasoning combinations of foreign productivity and domestic production costs such that the factors contribute equally to injury; let the curve USITC in figure 4.4 depict such combinations. The

26 The analysis here differs from the attribution analysis discussed above, in that the latter is about gaining information about the relative contributions of the various forces to serious injury, whereas the analysis here presumes that these developments are understood. It can thus be seen as comparing criteria used to evaluate the material provided by the attribution analysis. 


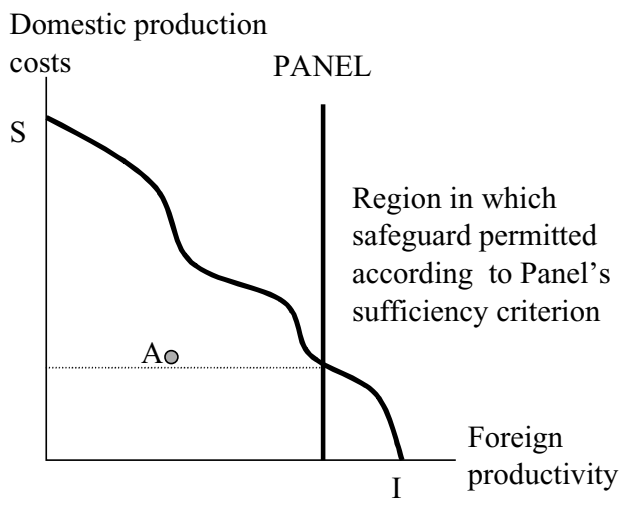

Figure 4.5

US International Trade Commission criterion would hence say that any combination of foreign productivity and domestic production costs such that both are in the "serious injury" region, and to the "south-east" of the USITC curve, would legitimize a safeguard.

Now turn to the Panel. According to (our understanding of) its interpretation, the foreign productivity increase must be both sufficient and necessary to cause serious injury, but need not be the sole cause of injury. Let us consider first the sufficiency part. It should be noted that in order to determine whether a foreign disturbance is sufficient to lead to serious injury, one cannot escape to specify the level of the other factor(s) for which the foreign shock is sufficient; as far as we can see, the panel did not specify this level. We will understand the Panel's argument as the requirement that the foreign productivity shock is sufficiently severe that it would lead to serious injury under "normal circumstances." Diagrammatically, this would mean that the foreign productivity and domestic production costs have to be to the "north-east" of the serious injury line, and to the "east" of the vertical line "PANEL" in figure 4.5.

The requirement that the foreign productivity increase is "necessary" for the injury to arise, is harder to understand. It seems to say that in the absence of this shock - which we take to be a situation of "normal" foreign productivity - no negative shock to domestic production costs would suffice to induce serious injury. This does not seem to us to be a sensible criterion; but maybe we have not fully understood the Panel's intentions.

Finally, turn to the AB. As far as we can see, it would allow a safeguard in any situation in the "serious injury" region. The fact that it will 


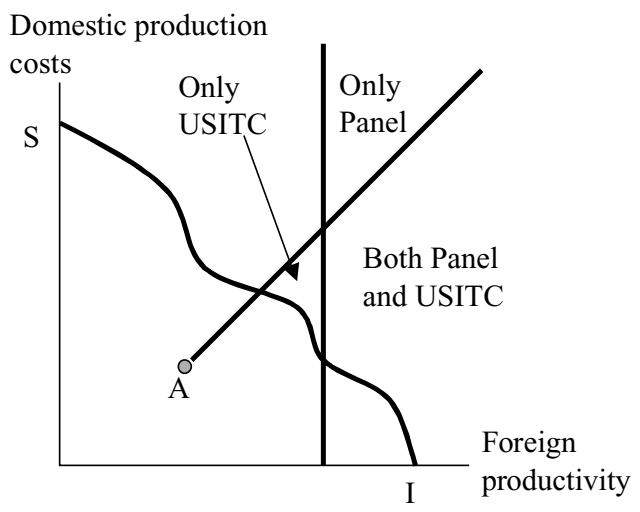

Figure 4.6

decompose the influences of the foreign productivity and the domestic production costs does not seem to hinder the imposition of a safeguard for a disturbance anywhere in this region, but possibly only the magnitude of the measure.

We can now compare the possibility of imposing safeguards using the three different criteria. A first observation is that the AB's criterion is actually more generous to safeguards than both the Panel's and the USITC criterion. In particular, the $A B$ criterion allows for safeguards in cases where the foreign productivity shock is not the main reason for the serious injury.

Secondly, it is not possible to unambiguously rank the Panel's criterion versus that of the US International Trade Commission. On the one hand, like the $\mathrm{AB}$, the Panel does not require that the foreign productivity shock is more important than other factors. On the other hand, the Panel requires (as we interpret it) that the foreign productivity shock must be sufficiently large in absolute magnitude, which is not required according to the Commission criterion. This is illustrated in figure 4.6, where the regions "Only Panel," "Only USITC," and "Both Panel and USITC" illustrate whether a safeguard would be permitted or not.

The differences between the various criteria are due to the fact that the Commission criterion for whether a safeguard is legal is relative, the Panel criterion is absolute, while the $\mathrm{AB}$ criterion includes all instances of serious injury.

There are two aspects that are missing from the simple illustration above, however. The first is that the discussion was concerned with a situation where there is only one external factor. Adding factors should 
not affect the AB's criterion, since it would just require that attribution be done with more factors. However, it is not clear exactly how the analysis should be done with several explanatory factors. But the US International Trade Commission criterion may be more sensitive: this criterion requires the foreign productivity increase to be no less important than any other cause. This raises the question of what is a cause? It seems as if with the US International Trade Commission method, one could always ensure that the effect due to any particular factor is always smaller than that of the increase in foreign productivity, by disaggregating factors finely enough.

\section{6 .2 "... threat of ..."}

A complicating factor in the present case is the fact that the dispute deals with an alleged threat of serious injury, rather than injury. There is in principle nothing wrong with such a use of an escape clause. However, it should only be legal under very special circumstances. It must thus be the case that unforeseen exogenous developments have led to a situation in which the country has not yet suffered injury, but in which the government is able to foresee with a high degree of certainty that serious injury is imminent. There has thus been a drastic change in the government's understanding of the situation in the industry.

Both the Panel and the AB acknowledge the fact that a "threat of" serious injury is distinct from serious injury that has already occurred. The Panel emphasizes the special requirements that the term "threat" imposes:

. . . an examination of the existence of threat of serious injury implies a future-oriented analysis of the domestic industry's condition which is distinct from an examination of whether actual serious injury exists.

It does think, however, that the method employed in the US International Trade Commission investigation suffices in this regard. The deficiency of the commission "threat of serious injury" - analysis is instead that the data it uses are not representative of the domestic industry. The $\mathrm{AB}$, on the other hand, questions the commission interpretation of the data. It points out that lamb-meat prices actually were higher at the end of the period of investigation than at the beginning of the period, and that the US International Trade Commission without explanation used prices from a period in between the endpoints as the benchmark, a period when prices were high. Furthermore, the Commission did not comment on the fact that prices rose sharply during the last months of the investigation 
period, a fact that would seem central to the determination of threat of injury:

Thus, if an industry is not yet in a state of serious injury, and that industry has enjoyed rising prices in the most recent past, it is, at least, questionable whether the industry is highly likely to suffer serious injury in the very near future. In such a situation, the competent authorities should devote particular attention to explaining the apparent contradiction between the most recent price rises and their view that the industry is still threatened with serious injury. In this case, the USITC offered no such explanation.

We agree with the adjudicating bodies that there should be an especially onerous burden of proof in cases of not yet materialized injury. As discussed above, in order to show causality one needs a theory of how external factors threaten to cause injury. Such a theory by necessity has to be dynamic in the context of threat of injury, and this is bound to make it complex. Also, it is neither necessary nor sufficient to verify empirically that the industry presently is suffering injury. Instead a high probability of imminent future injury must be demonstrated.

\section{6 “...necessary...”}

Article XIX GATT requires that the safeguard is necessary to prevent serious injury. A central aspect of this is clearly whether the magnitude of the safeguard is appropriate. Having found the safeguard unwarranted in the first place, the Panel and the $\mathrm{AB}$ reports do not discuss this aspect. We would however like to make a few reflections on this issue.

Consider the framework employed above to highlight the criteria employed by the US International Trade Commission, the Panel, and the AB. Suppose foreign productivity and domestic production costs both increase, and that the new situation is associated with serious injury according to all three criteria. The question is then: how large could this safeguard legally be? Article XIX.1.a GATT limits the magnitude by requiring that it is "... to the extent and for such time as may be necessary..." There are several possible interpretations of this term, however.

Consider the graphical illustration in figure 4.7, where the point D represents the situation of injury. Note that a safeguard in the form of a tariff would, from a domestic production point of view, be equivalent to a reduction in the foreign productivity, and would thus essentially shift the point $\mathrm{D}$ horizontally inwards. One possibility would be that once 
Domestic production

costs

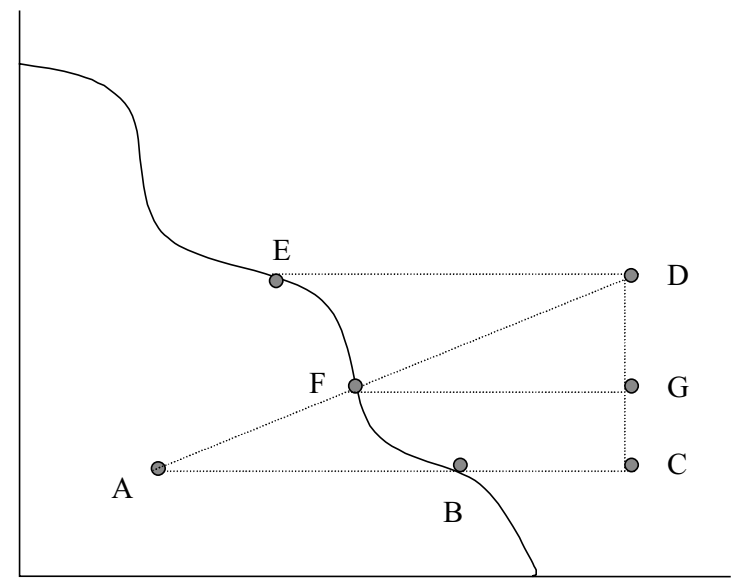

Foreign

productivity

Figure 4.7

permitted, the safeguard could be large enough to just undo the serious injury situation; this would amount to a safeguard equal to the horizontal distance between D and E; the US International Trade Commission criterion seems to be pointing in this direction.

Another possibility would be to argue, perhaps more in line with the $\mathrm{AB}$, that it is only the share of serious injury that is attributable to the foreign productivity increase that should be offset. This attribution can in turn be done in different ways. For instance, decomposing the shift from A to $D$ into a move from $A$ to $C$, and from $C$ to $D$, it could be argued that had it not been for the domestic production cost increase given by the distance between $C$ and $D$, it would have sufficed with a safeguard equal to the distance between $\mathrm{B}$ and $\mathrm{C}$. Another possibility might be to argue that when the industry moved from its "normal" state A to state D, it was at point $\mathrm{F}$ that the injury became serious. Hence, the share of the "blame" that should fall on foreign productivity is given by the distance between points $F$ and G. In neither of these cases would the safeguard suffice to completely offset the state of serious injury.

It can be noted that, to the extent that our interpretations of the intentions of the US International Trade Commission and the AB are correct, while the Commission has a stricter criterion than the $\mathrm{AB}$ for determining whether safeguards are permitted at all, it allows for more trade-restricting 
measures in cases where they are permitted. Hence, it is unclear which is overall the more stringent criterion.

One might also conceive of other criteria for determining the magnitude of safeguards. The conclusion is thus that the interpretation of the "... to the extent ... necessary ..." criterion is far from self-explanatory, and that the interpretation might have important effects for the extent to which safeguards can be used.

\section{7 “... of the effect of obligations incurred under this Agreement ..."}

Article XIX.1.a requires that unforeseen increase in imports results from "... the effect of obligations incurred under this Agreement ..." This criterion has in case law largely been neglected, and so also in US - Lamb. There seem to be quite good reasons for this neglect.

A first problem is the interpretation of the obligations and the Agreement to which the text refers. "This Agreement" is presumably GATT 1947, indicating that liberalization that was effectively undertaken already under previous rounds should not be "counted," since industry has had time to adjust to this earlier liberalization. To take an example: suppose that pre-GATT 1947 the tariff was 30\%, that it was reduced to $15 \%$ through the rounds before GATT 1994, and that it was reduced further to $10 \%$ in the Uruguay Round. In such a case, it is only the cut from $15 \%$ to $10 \%$ that would serve as the basis for a safeguard. But for how many years after the reduction from $15 \%$ to $10 \%$ should have been implemented is the Member then allowed to invoke a safeguard? An alternative interpretation, however, is that the alternative to the $10 \%$ level is not $15 \%$, but the level that the country would choose, did GATT not exist at all. The former interpretation seems to us to be more reasonable, but the wording of the text is sufficiently ambiguous to allow for both interpretations.

A second problem with the notion of "this Agreement" is that it is not clear that it is warranted, if interpreted as referring to liberalization that has occurred through the agreement on GATT 1994. One can conceive of two main types of situations that this term seeks to address. The first is a safeguard that is invoked in a situation where liberalization has occurred but not under the Agreement, that is, when a Member has liberalized unilaterally. As far as we can see, there is no particular reason not to allow safeguards in these cases. Unilateral liberalization benefits trading partners just as negotiated liberalization (except that it is not "locked in" though an agreement). It would be detrimental to the incentives to 
undertake unilateral liberalization not to allow safeguards in situations where this liberalization is partly the reason for a situation of serious injury.

More difficult is the question of whether a safeguard should be allowed in a situation where a Member did not make any concession during the most recent round. Intuitively, it might seem doubtful whether a safeguard should be permitted, since the Member was not very forthcoming in the last round. However, in order to determine whether this is a reasonable ground for rejecting the possibility of using a safeguard, one would also have to consider the reasons for this unwillingness to liberalize. The industry at hand is perhaps very sensitive to the Member in question, and the level at which the tariff was bound may as such represent a significant sacrifice to the Member, even if the Member negotiated the same level in the previous round. It is possible that the Member might have chosen a higher bound level, were it not for the possibility to invoke a safeguard, should the threat of serious injury arise.

The reference to obligations incurred under the agreement must be seen as the context for safeguards: what is probably meant through this phrase is that safeguards might prove necessary in a context of trade liberalization. However, the interesting question would be the extent to which safeguard measures should be possible independently of whether the items are bound or unbound. There are some good arguments in favor of restricting safeguard actions to the former category only. In such a case, for bound items, Members would have a choice between either raising tariff duties by paying compensation, which would require time-consuming Article XXVIII GATT negotiation, or to unilaterally impose safeguards. The possibility of using quantitative safeguards would then be restricted to the bound items. But on unbound items Members would still have the possibility of responding to adverse developments by raising tariffs to prohibitive levels. They might in principle run the risk of facing a nonviolation complaint. Keeping in mind, however, that standing case law has made it clear that such complaints are permissible only if concessions have been exchanged, this does not seem to be a promising perspective legally.

\section{Concluding remarks}

We believe that the basic verdict in US - Lamb - the illegality of the US safeguard - is correct. We also believe that the reason for the ruling - the methodological deficiencies of the US International Trade Commission investigation - is correct as well. 
In our view, US - Lamb points to two systemic problems. First, the text requires that the cause of serious injury, or the threat thereof, is increased imports. But imports are not determined exogenously, they are typically the net result of thousands and thousands of decisions by producers, consumers, and governments. In other words, imports are a proximate but not the ultimate cause of injury. The Agreement on Safeguards, however, makes it clear that proximate causes suffice for a lawful imposition of safeguards. But allowing safeguards in response to increased imports in general could invite moral-hazard-like problems. To avoid such problems, a basic issue is to determine the sources of disturbances that should be legitimate grounds for safeguards, among all those causing increased imports. This is an issue on which the WTO Agreement is silent, and in this regard, we see a weakness in the text governing safeguards.

Second, there are problems relating to the standard of review, and, in particular, to the requirements that should be demanded from a country imposing a safeguard. We believe that some form of quantitative analysis should normally be a necessary but insufficient component to verify "unforeseen developments" and "causality." ${ }^{27}$ Such quantification is also required in order to demonstrate the necessity of the chosen magnitude of the safeguard. It might be argued that the adjudicating bodies are constrained by the material and analysis provided by the parties, and thus are not to be blamed for the unsatisfactory analytical level in this dispute. Furthermore, the $\mathrm{AB}$ in this case actually did rule that the US had not shown causality. However, we feel that the adjudicating bodies could have given clearer guidance to the parties concerning the requirements of such an analysis.

One counter-argument to the demand for a more solid quantitative analysis in safeguard cases could be that there are a number of methods that seek to identify and characterize the statistical relationship between endogenous and exogenous variables. Each has its theoretical and practical drawbacks, and no single method can therefore claim to provide the test of causality or be the tool to use for non-attribution analysis. But, the fact that none of the methods is perfect does not mean that none should be applied, since the lack of quantitative methods is likely to invite even more arbitrariness.

${ }^{27}$ Indeed, as the subsequent $\mathrm{AB}$ report on Line Pipe itself acknowledged, the attribution exercise is a formidable task, which however has been imposed on all WTO Members. We should note here, however, that the $\mathrm{AB}$ made its comments in this respect when dealing with Article 5.1 SG and not with Article 4.2 SG. 
Another counter-argument might be that increased requirements for safeguard investigations would disadvantage developing countries, since they might not have the resources to undertake such quantification. This is clearly an argument that needs to be taken seriously. However, we believe that many developing countries have indeed the capacity to undertake at least a basic quantitative analysis. And if a country cannot perform such an analysis, one may wonder, how does it know the source of the injury? Also, whether developing countries would gain or lose from such an increase in the requirements for a safeguard investigation depends not only on how their ability to impose safeguards is affected. It will also depend on the extent to which they will be less exposed to safeguards in their export markets.

Finally, one should not expect econometric or other quantitative methods to provide a "bright line." On the contrary, the systematic introduction of such methods will make the adjudication process more complex, and would make the adjudicating bodies dependent on expert witnesses, as long as such expertise is not incorporated into these bodies. ${ }^{28}$ But there is something fundamentally unsatisfactory about a state of affairs where there exists a science that is largely devoted to developing methods for determining causality and attribution, and, at the same time, WTO Members almost completely ignore its existence in their investigations concerning the very same issues. It is the role of adjudicating bodies to sensitize investigating authorities in this respect.

\section{References}

Bhagwati, Jagdish. 1981. Import Competition and Response. Chicago, IL: University of Chicago Press.

Deardorff, Alan. 1987. Safeguards Policy and the Conservative Social Welfare Function. In Henryk Kierzkowski, Protection and Competition in International Trade: Essays in Honor of W. M. Corden. Blackwell: Oxford.

Dixit, Avinash. 1987. Trade and Insurance with Moral Hazard. Journal of International Economics, 23: 201-20.

Dixit, Avinash. 1989a. Trade and Insurance with Imperfectly Observed Outcomes. Quarterly Journal of Economics, February: 195-203.

1989b. Trade and Insurance with Adverse Selection. Review of Economic Studies, 56: $235-48$.

${ }^{28}$ The WTO Research Division could play an important role in this regard. 
Eaton, Jonathan and Gene Grossman. 1985. Tariff as Insurance: Optimal Commercial Policy when Domestic Markets are Incomplete. Canadian Journal of Economics, 18: 258-72.

Grossman, Gene. 1986. Imports as a Cause of Injury: the Case of the U.S. Steel Industry. Journal of International Economics 121.

Irwin, Douglas A. 2002. Causing Problems? The WTO Review of Causation and Injury Attribution in U.S. Section 201 Cases. Mimeo.

Kelly, Kenneth. 1988. The Analysis of Causality in Escape Clause Cases. Journal of Industrial Economics, 37: 187-207.

Mussa, Michael. 1981. Government Policy and the Adjustment Process. Pp. 73-120 in Jagdish Bhagwati, Import Competition and Response. Chicago, IL: University of Chicago Press.

Neary, Peter. 1981. Inter-Sectoral Capital Mobility, Wage Stickiness, and the Case for Adjustment Assistance. Pp. 39-67 in Jagdish Bhagwati, Import Competition and Response. Chicago, IL: University of Chicago Press.

Newbery, David M. G. and Joseph E. Stiglitz. 1981. The Theory of Commodity Price Stabilization. Oxford: Oxford University Press.

Pindyck, Robert and Julio Rotemberg. 1987. Are Imports to Blame? Attribution of Injury under the 1974 Trade Act. Journal of Law and Economics, 30: 101-22.

Sykes, Alan. 1990. GATT Safeguards Reform: the Injury Test. In Michael Trebilcock and R. York, Fair Exchange: Reforming Trade Remedy Laws. Policy Study 11. C. D. Toronto: Howe Institute.

1991. Protectionism as a "Safeguard': a Positive Analysis of GATT Article XIX with Normative Speculations. University of Chicago Law Review, Winter. 